\title{
O JOGO DE BOLÃO EM CLUBES TEUTO-BRASILEIROS (DÉCADAS DE
} 1860 A 1920) ${ }^{1}$

\author{
Recebido em: $13 / 08 / 2020$ \\ Aprovado em: 15/12/2020 \\ Licença:@) (1) @ \\ Alice Beatriz Assmann ${ }^{2}$ \\ Universidade do Estado de Minas Gerais (UEMG) \\ Divinópolis - MG - Brasil \\ Carolina Fernandes da Silva ${ }^{3}$ \\ Universidade Federal de Santa Catarina (UFSC) \\ Florianópolis - SC - Brasil \\ Janice Zarpellon Mazo ${ }^{4}$ \\ Universidade Federal do Rio Grande do Sul (UFRGS) \\ Porto Alegre - RS - Brasil
}

RESUMO: O presente estudo busca identificar as composições da prática do bolão em associações esportivas étnico-culturais teuto-brasileiras, realizando uma leitura do tempo demarcada entre as décadas de 1860 e 1920. Para tal, foram cotejados documentos impressos e imagens com as informações coletadas na revisão bibliográfica. Os primeiros indícios da prática do bolão (Kegeln) em Santa Cruz do Sul estão datados em 1866, quando foi construída uma cancha de bolão pela Schützengilde (Corporação de Atiradores) e foi fundado o Clube União. A prática do bolão foi incorporada pela Sociedade Ginástica de Santa Cruz do Sul, em 1916, no período da I Guerra Mundial. Diferentemente de outras práticas identificadas com os teutobrasileiros, os torneios competitivos de bolão mantiveram-se apesar das intempéries decorridas com a I Guerra. Além de prática de lazer, jogo de bolão era utilizado como um meio de arrecadar recursos financeiros.

PALAVRAS-CHAVE: Bolão. Clubes. Imigração Alemã.

\section{KEGELN IN GERMAN-BRAZILIAN CLUBS (FROM 1860's TO 1920's)}

\footnotetext{
${ }^{1}$ Pesquisa financiada pela Coordenação de Aperfeiçoamento de Pessoal de Nível Superior - CAPES.

2 Doutora em Ciências do Movimento Humano. GEPESEFE - Grupo de Estudos e Pesquisas Socioculturais em Educação Física e Esporte.

3 Doutora em Ciências do Movimento Humano. Sôma - Núcleo de Estudos em Cultura, Corpo e Movimento

${ }^{4}$ Doutora em Ciências de Desporto. NEHME - Núcleo de Estudos em História e Memória do Esporte e da Educação Física.
} 
ABSTRACT: This study seeks to identify the compositions of the practice of the draw
in German-Brazilian ethnic-cultural sports associations, performing a reading of the
time demarcated between 1860's and 1920's. To this end, printed documents and
images were compared with the information collected in the bibliographic review. First
evidences of the practices of Kegeln in Santa Cruz do Sul is dated in 1866, when a
Kegeln court was built by Schützengilde (Shooter Corporation) and the Union Club was
founded. The Kegel practice was also incorporated by the Gymnastic Society of Santa
Cruz do Sul, in 1916, in the period of World War I. Differently from other practices
identified with the German-Brazilians, Kegeln competitive tournaments and social
festivities continued despite the bad weather during the World War I. In addition to
leisure practice, the Kegeln game was used as a means of raising financial resources.
KEYWORDS: Kegeln. Clubs. German Immigration.

\section{Introdução}

Os imigrantes alemães e seus descendentes organizaram associações voltadas a diferentes práticas esportivas no Rio Grande do Sul, especialmente, após a década de 1860 (ROCHE, 1969). Dentre as associações estão as de tiro ao alvo (ASSMANN; MAZO, 2012), sociedades de cavalaria (KIPPER, 1967), de ginástica (KILPP, 2012; SILVA, 2005; TESCHE, 2001), de remo (SILVA; MAZO; TAVARES, 2018), de tênis (PEREIRA; MAZO; BALBINOTTI, 2010), de futebol (MASCARENHAS, 2001), entre outras, situadas em diferentes regiões do estado. A perspectiva associativa, onde os membros pagavam uma mensalidade, era a principal forma de manutenção destes espaços, porém para novos investimentos, eram necessárias novas alternativas.

Entre estas, podemos destacar as competições organizadas em formato de campeonatos de lazer com inscrição e ingresso, como os jogos de bolão (Kegeln), os quais atraiam participantes e expectadores que buscavam o caráter autotélico do ato de jogar (SUITS, 1978). Além dos jogadores, há circunstâncias que o jogo do bolão, também, mobiliza de forma intensa os espectadores.

Nesta direção, Huizinga (1996, p. 84) afirma que jogar "envolve atividade livre, conscientemente realizado como 'não-séria' e fora da vida normal, mas ao mesmo tempo capaz de absorver o jogador intensamente e de forma integral". Da Alemanha 
disseminou-se para outros países.Praticado na Alemanha desde 1768, o jogo do bolão consiste em derrubar o maior número de pinos jogando cinco bolas. Este jogo era/é semelhante ao boliche, com algumas diferenças, quanto: ao formato da cancha, ao número de pinos (nove), ao material e peso da bola, que pode variar de 10 a $11 \mathrm{~kg}$ (KILPP; MAZO; LYRA, 2010).O jogo, conforme Caillois (CAILLOIS, 1986),pode ser considerado essencialmente como uma atividade livre, atraente, divertida e agradável; delimitada em um espaço e tempo específico; incerta, com um pouco de liberdade para criar; improdutiva, por não trazer algumas propriedades; regulado, com regras específicas; e fictícia, ou seja, diferente da vida real.

Cabe destacar que, a improdutividade apresentada por Caillois (1986) está relacionada com a concepção de não criar bens ou riquezas no espaço e tempo do jogo, diferentemente de utilizar-se de uma organização da prática, como competições, para fins de manutenção das atividades associativas e, assim, proporcionar novos momentos para o ato de jogar. Diante disso, pensa-se o jogo de bolão a partir da complexidade que envolve o lazer (MARQUES, 2012).

No Brasil, o bolão foi difundido em regiões onde se instalaram imigrantes alemães como o Rio Grande do Sul (RS) e, neste estado, na localidade de Santa Cruz do Sul, a partir da segunda metade do século XIX. Segundo Mazo (MAZO, 2005), era conhecido como o "jogo da bola" ou "Esporte dos 9 paus". A prática era realizada em “canchas feitas de barro, areia e até mesmo, lascas de árvores de coqueiro, seguindo diferentes regras, de acordo com a região de origem dos imigrantes alemães" (MAZO, 2005, p. 1). Tais representações desta prática estão relacionadas com a perspectiva histórica regional, “uma vez que as circunstâncias históricas responsáveis por explicar o desenvolvimento desta e de outras técnicas corporais, não necessariamente estarão 
presentes nos mesmos termos e da mesma forma em todas as regiões do país" (DIAS, 2014, p. 386).

Município do estado do Rio Grande do Sul, Santa Cruz do Sul foi instituído como colônia alemã, no ano de 1849 (MARTIN, 1979), um empreendimento público, habitado majoritariamente por imigrantes e descendentes de alemães, e por eles culturalmente germanizados, assumindo características específicas. Seyferth (2000) afirma que o termo "colônia alemã" indica uma especificidade linguística, bem como, uma organização comunitária e estilo de vida específico. Tais representações se constituíam em formações identitárias desses grupos, as quais foram intensamente contestadas durante o período da Primeira Guerra Mundial (1914-1918), principalmente quando o Brasil se insere nesse conflito bélico e começam um movimento de nacionalização das associações esportivas (MAZO, 2007).

No decorrer dos anos, imigrantes alemães e descendentes que habitavam a região de Santa Cruz do Sul fundaram associações esportivas. Assmann (2015) contabilizou, aproximadamente, 100 associações esportivas, entre 1860 e 1920, na localidade com destaque para as práticas esportivas do tiro ao alvo, lançaria, ginástica, futebol, tênis e o bolão. Dentre essas associações, a mesma autora aferiu 14 canchas, grupos ou clubes de bolão no período demarcado, do total de aproximadamente 100 clubes que ofereciam distintas práticas esportivas entre as décadas de 1860 e 1920 (ASSMANN, 2015). Período este alocado entre os primeiros vestígios encontrados sobre prática do bolão e as repercussões dos acontecimentos da Primeira Guerra Mundial (1914-1918) no Brasil, em particular nas regiões com acentuada presença de imigrantes alemães e descendentes.

Diante de tal panorama, este estudo busca identificar as composições do jogo do bolão em associações esportivas étnico-culturais teuto-brasileiras, realizando uma 
leitura do tempo demarcada entre as décadas de 1860 e 1920 . O recorte temporal dos acontecimentos deste estudo se localiza em um período do passado, assim a presente pesquisa histórica coaduna com a perspectiva de Roger Chartier (CHARTIER, 2009). Para este autor, seria mais adequado falar em uma leitura do tempo, uma narrativa com intenção de verdade, que procede a uma verossimilhança. Além disso, também acreditamos que o passado é a meta e a operação historiográfica é a forma do historiador de se aproximar dessa meta (JENKINS, 2004). Para Pesavento (2004), o tempo histórico seria o "terceiro tempo", aquele reconfigurado pela narrativa sobre o tempo escoado, não vivido, não experimentado. Com o olhar lançado para as especificidades da prática do bolão nos contextos locais das regiões do Rio Grande do Sul buscamos interpretar o modo de viver no mundo dos imigrantes alemães e seus descendentes e, assim contribuir para uma ampliação da compreensão do cenário de práticas corporais e esportivas no Brasil.

A fim de alcançar o objetivo proposto neste estudo e construir uma narrativa acerca das composições do bolão em associações esportivas étnico-culturais teutobrasileiras, elegeu-se a localidade de Santa Cruz do Sul, devido a sua história marcada pela imigração alemã. Para tanto, recorreu-se a uma revisão bibliográfica acerca do tema e à coleta de informações em documentos impressos, como periódicos e livros comemorativos. Cabe destacar que parte das informações foram coletadas no jornal Kolonie, veiculado integralmente em alemão na região de Santa Cruz do Sul, no período de 1891 a 1941. Este periódico dirigido à comunidade teuto-brasileira local foi o primeiro jornal editado fora da região de Porto Alegre, capital do estado, e de São Leopoldo, primeira Colônia Alemã do Rio Grande do Sul, com tais fins (WESCHENFELDER, 2010). 
No tratamento da documentação coletada, os jornais são entendidos não como portadores de verdades, mas como instrumentos que trazem uma percepção do acontecido, como os demais documentos que compõe o corpus documental desta pesquisa. Zicmann (1985, p. 90) refere-se aos jornais como "arquivos do quotidiano", cujas informações "denotam as atitudes próprias de cada veículo de informação", que as organiza "segundo seu próprio "filtro"”. Para o presente estudo, tal perspectiva é ressaltada visto que até 1945/1950 a imprensa brasileira caracterizava-se como uma “imprensa de opinião", ancorada em pequenas empresas, de gestão improvisada, com ênfases políticas explícitas e um tipo específico de público-leitor alvo (ZICMANN, 1985).

De acordo com Calonga (2012, p. 85), “os impressos são produtos forjados a partir de representações contextualizadas da realidade. O que, invariavelmente, revelam formas simbólicas de luta pelo poder de representar". Vistos como produtos do tempo, os impressos são compreendidos enquanto espaços de representações do real, de produção e manifestação de discursos localizados e posicionados histórica, social e culturalmente, para consumo de determinado público. Este instrumento, quando cruzado com as demais fontes desta pesquisa, se torna um importante meio de compreensão de um tempo passado. No tópico que segue buscamos delinear as formas elementares da prática do jogo do bolão no estado do Rio Grande do Sul, a partir de vestígios do passado.

\section{Vestígios da Disseminação do Jogo do Bolão no Rio Grande do Sul}

No Rio Grande do Sul, os contextos de inserção do jogo do bolão apresentam diferentes configurações, dentre as quais destaca-se Santa Cruz do Sul como espaço de constituição de canchas de bolão já em meados do século XIX, construídas por 
iniciativas particulares e com fins específicos. Seja para divertimento ou outros propósitos. "As canchas primitivas (...) eram faixas de terra batida e socada, às vezes misturada à areia, sobre as quais eram arremessadas bolas de madeira, que deveriam atingir um determinado número de paus assentados na outra extremidade" (KRELING, 1984, p. 24). Tais canchas, segundo Kreling (1984), eram localizadas, geralmente, junto a um armazém ou bodega, como "atrativo para a freguesia" e um divertimento aos domingos. Assim como apontado por Caillois (1986), um divertimento livre e agradável, com espaço, tempo e regras delimitados. Para além das casas comerciais, também se encontravam canchas de bolão junto a casas de bailes.

As canchas de prática, também conhecidas como pistas, eram diferenciadas de acordo com sua especificidade no idioma alemão: as canchas de areia eram denominadas Sandbahn, enquanto as canchas de barros recebiam denominações como Dreckbahn, Lehmbahn, Lettenbahn, Grundbahn, a depender da região. Tal diferenciação, possivelmente, está relacionada à localidade de emigração dos grupos e sujeitos que se apropriaram da prática. As pistas, chamadas por Kreling (1984) de "primitivas", foram aos poucos sendo substituídas por pistas mais sofisticadas, de madeira. A bola poderia ter dois furos para os dedos ou não ter nenhum, sendo então chamada de PanzKugel (bolão de barriga). Esta última era proibida às mulheres, devido às frequentes quedas provocadas pela forma do arremesso. Contudo, isto não significa que as mulheres não praticassem, encontrando formas de burlar as regras sociais. Segundo Kreling (1984, p. 25), “em Santo Inácio da Feliz5 , por volta de 1900, as irmãs Eleonora e Amalia Ruschel, divertiam-se, às ocultas, jogando o PanzKugel”.

O jogo do bolão era praticado, primeiramente, em ambiente aberto. As sociedades com espaço coberto para a prática foram constituídas mais tarde. As

\footnotetext{
${ }^{5}$ Santo Inácio da Feliz refere-se, possivelmente, à paróquia de Alto Feliz, localidade colonizada por imigrantes alemães e italianos, emancipada da cidade de Feliz/RS em 1992.
} 
associações (grupos ou clubes) (SILVA; MAZO, 2015) voltadas para a prática do bolão nas regiões de imigração alemã eram chamadas de Kegelklub (Clube de Bolão) ou Kegelverein (sociedade de bolão) (FACHEL, 1964).

A capital do estado, Porto Alegre, que contava com diversos representantes alemães e teuto-brasileiros, Silva (2003) diz que um viajante teuto-norte-americano, que esteve em Porto Alegre em 1881, exclamou que "em toda parte se vislumbram sinais da presença de comerciantes alemães: na esquina se ouve a língua da pátria de origem. Nesse local, a prática do bolão é mais tardia em relação à Santa Cruz do Sul. Diante disso, localizou-se uma cancha de bolão no ano de 1873 , pertencente a um imigrante alemão e, somente após uma década, em 1885, a fundação de um clube, o Musterreiter Klub, que além da prática de tiro ao alvo também inseriu o bolão (MAZO, 2005). Um grupo específico de bolão, denominado "Grupo de Bolão 14", foi organizado na capital no final do século XIX, em 1896, pela Gesellschaft Leopoldina (Associação Leopoldina) (MAZO, 2003).

Em Agudo/RS, também existiram associações específicas para a prática do bolão. Contudo, segundo o Livro Comemorativo de 75 anos de Agudo (75 JAHRE..., 1932), para além destas, as sociedades de atiradores e outras associações mantinham canchas de bolão em suas dependências. No referido livro, consta que o bolão é um jogo "muito antigo", remetendo aos antigos "germânicos" representados em uma fotografia como ilustração (75 JAHRE..., 1932, p. 178). Nesta imagem, percebe-se um grupo constituído apenas por homens com diferentes faixas etárias, vestindo terno e chapéu marcando distinção social, posicionados para a fotografia (alguns sentados e outros em pé), tendo a frente os equipamentos (pinos e bolas), usados no jogo de bolão, colocados no centro e ladeados por dois meninos jovens. 
Diante desse cenário, o bolão encontra-se como uma prática disseminada no estado e vinculado a uma identidade específica, manifestada e negociada por teutobrasileiros, os quais se fixaram também em Santa Cruz do Sul, fundaram seus clubes e desenvolveram suas práticas, como o bolão.

\section{O Jogo Bolão em Clubes de Santa Cruz do Sul}

Segundo Oliveira (OLIVEIRA, 1996), o grupo de bolão mais antigo do estado do Rio Grande do Sul foi fundado em 1883 pela Sociedade Orfheu de São Leopoldo. No entanto, Klaus Becker discorda e afirma que a primeira cancha de bolão do estado do Rio Grande do Sul foi instalada em Santa Cruz do Sul, no ano de 1868, pelo açougueiro Miguel Cobia, proprietário da Gastwirtschaft (hospedaria) chamada Zum Deutschen Miguel Cobia. Uma terceira versão é ainda narrada por Martin (1999) e Müller (2006). Conforme Müller (2006), o Clube União ${ }^{6}$ foi a primeira associação do estado do Rio Grande do Sul específica para a prática do bolão. O autor confirma a data de construção da primeira cancha de bolão em Santa Cruz do Sul, mas atribui o episódio ao Clube União. Entretanto, há evidências que corroboram com a alegação de Klaus Becker no que se refere ao pioneirismo do bolão em Santa Cruz do Sul, não apenas quanto à construção da primeira cancha do jogo, mas também a prática institucionalizada em clubes. Desta maneira, o jogo do bolão emerge como uma nova alternativa aos frequentadores destes espaços, como na Schützengilde (Corporação de Atiradores). Fundada em Santa Cruz do Sul no ano de 1863 pela iniciativa de imigrantes alemães, a Schützengilde fomentava nos primeiros anos a prática de tiro ao alvo e de cavalaria ${ }^{7}$. Em 1866, a associação inaugurou a sua primeira cancha de bolão para o

\footnotetext{
${ }^{6}$ Segundo Burgos (2005) o Clube União era a associação mais antiga, ainda em atividade, na cidade de Santa Cruz do Sul. Todavia, no ano de 2017, uniu-se ao clube Corinthians e suas dependências foram vendidas.

${ }^{7}$ Prática realizada com o cavalo e consistia em acertar um alvo feito de couro com uma lança (KIPPER, 1967).
} 
desenvolvimento da prática pelos associados, a qual se perpetuou mesmo quando a Corporação de Atiradores se juntou, no ano de 1868, com o Club Union (Clube União) (MARTIN, 1999).

A prática do bolão se propagou de forma significativa para além da Corporação de Atiradores e do Clube União em Santa Cruz do Sul, por meio da organização de clubes/grupos de bolão, como é possível observar no Quadro abaixo.

\begin{tabular}{|c|c|c|c|}
\hline Associaçãoesportiva & $\overline{\text { Prática(s) }}$ & Ano fundação & Localidade $^{8}$ \\
\hline Schützengilde & $\begin{array}{c}\text { Tiro ao alvo } \\
\text { Cavalaria } \\
\text { Bolão }\end{array}$ & 1863 & Vila Santa Cruz \\
\hline Clube União & Bolão & 1866 & Vila Santa Cruz \\
\hline Millionenklub (Clube União) & Bolão & $<1891$ & Vila Santa Cruz \\
\hline Turnverein Santa Cruz & $\begin{array}{c}\text { Ginástica } \\
\text { Bolão }\end{array}$ & 1893 & Santa Cruz \\
\hline Club Terminante & Bolão & $<1899$ & Não localizada \\
\hline KegelklubNordpol-Expedition & Bolão & $<1899$ & Não localizada \\
\hline KegelclubNeuntöter & Bolão & $<1899$ & Rettungspikade \\
\hline Club Jogo de Bolas "Rio Grandense" & Bolão & $<1900$ & Vila Santa Cruz \\
\hline Club "GutHolz" & Bolão & $<1900$ & Não localizada \\
\hline KegelklubBlauerMontag & Bolão & 1914 & Santa Cruz \\
\hline Kegelklub "Maçaneta" & Bolão & $<1915$ & Santa Cruz (Aliança) \\
\hline Kegel-BahnDamenkegeln & Bolão & 1917 & Não localizada \\
\hline Tigre & Bolão & 1918 & Santa Cruz \\
\hline KegelKlub Sinimbu & Bolão & 1922 & Sinimbu \\
\hline
\end{tabular}

Fonte: quadro adaptado de Assmann (2015)

Quanto aos eventos promovidos pelas associações de bolão, eram realizados torneios para consagração do rei da associação, distribuição de prêmios aos participantes e festividades com música e bebidas. Para a escolha de novos sócios, era utilizado o sistema da balotagem (ASSMANN, 2015), o qual se caracteriza pela escolha dos associados através da utilização de bolas brancas e pretas como forma de votar. A votação era realizada da seguinte maneira: quem era a favor da entrada do novo sócio, depositava em uma "caixinha" uma bola branca, quem era contra, depositava uma bola preta. Após a coleta do voto de todos os associados, as bolas eram contadas e o maior número de bolas brancas significava a aprovação do novo sócio, de bolas pretas, o veto.

\footnotetext{
${ }^{8}$ Localidades que, no período histórico que abarca esse estudo, pertenciam a Santa Cruz do Sul.
} 
Esse sistema possibilitava que os associados selecionassem os indivíduos que deveriam ser incluídos e excluídos do grupo. Importa destacar que os eventos mencionados, bem como o sistema de votação, eram semelhantes àqueles desenvolvidos pelas associações de atiradores e cavaleiros.

Não foi localizado documento de associações que explicitasse critérios para inclusão de novos sócios. Todavia, quando Fachel (1964) menciona que a maioria dos sócios era composta por imigrantes alemães e seus descendentes, sendo o uso do idioma alemão corrente em 1963 e ainda havia sócios que não se comunicavam em língua portuguesa, fornece indícios que sugerem critérios velados. Ramos (2000) aludiu que as festividades promovidas pelas associações com marcadas representações identitárias étnico-culturais teuto-brasileiras se constituíam na expressão máxima da germanidade. Tanto as festas e competições que proclamavam o rei, festividade comum às associações de tiro ao alvo, bolão e cavaleiros, também aparecem como meios de representação e identificação do grupo interna e externamente (ASSMANN; MAZO, 2017, p. 489-503).

Diferentemente das demais práticas esportivas evidenciadas por Assmann (2015), contudo bolão não parece ter sido apropriado - de modo específico - como estratégia de promoção ou manutenção de uma cultura germânica. Além de espaço social, de convívio com os amigos, integração e entretenimento, o jogo do bolão foi apropriado como meio utilitário, uma forma de alavancar o capital econômico. As canchas eram, muitas vezes, utilizadas para angariar fundos e outros fins, que extrapolavam a prática do jogo propriamente e o divertimento. Fachel (1964, p. 319) afirmou que as associações de bolão funcionavam, geralmente, “junto às casas de negócio do interior”. Cabe lembrar que a primeira cancha de bolão foi construída pela Schützenverein Santa Cruz, associação que se localizava junto a uma cervejaria. "Assim como o artesanato se 
constituía em complemento para assegurar a manutenção da família do colono, o bolão exerceu o mesmo papel entre os comerciantes" (KRELING, 1984, p. 29). Ademais, a entidade supracitada caracterizava-se por compor um quadro social associado à elite local. A instalação de uma cervejaria e uma cancha de bolão junto a um clube social que reunia sujeitos com capital econômico para consumo pode evidenciar uma estratégia comercial orientada ao lucro. Tais informações vão ao encontro do estudo de Kilpp; Mazo e Lyra (2010), sobre as associações esportivas da localidade de Teutônia/RS, as quais inferem que as canchas de bolão foram construídas por proprietários de armazéns comerciais a fim de gerar lucros com a venda de produtos aos praticantes.

Mazo (2005) verificou que o jogo do bolão, para além de um meio para arrecadar valores como estratégia comercial, poderia também abarcar apostas.Como jogos de azar, os expectadores/apostadores poderiam encontrar o risco impresso no jogo, assim como a tentativa de buscar um resultado previsto e permitiam aos jogadores e/ou expectadores receber "por fortuna ou por desgraça, sem nada poder fazer, a uma aptidão para tirar o melhor partido dos seus desiguais recursos" (CAILLOIS, 1986).

A inauguração de canchas em estabelecimentos comerciais, bem como disputas de jogos de bolão eram anunciados em jornais que circulavam na época, inclusive, no princípio do século XX, com ilustrações. Um exemplo é a publicação do Kolonie (RETTUNGS-PIKADE, 1910) sobre uma associação esportiva de bolão de Santa Cruz do Sul, a qual chamou a atenção devido à ilustração apresentada. Nesta estão representados os nove pinos, a bola utilizada para a prática e um personagem que parece estar festejando a sua jogada, pois está de braços abertos, segurando um gorro em uma das mãos e gritando de felicidade. No que refere a sua vestimenta, as calças são remendadas e o sapato difere-se daqueles calçados usados pelos homens presentes na imagem fotográfica comentada anteriormente com relação à Agudo (75 JAHRE..., 
1932), bem como em outras imagens coletadas acerca de grupos e bolão no sul do Brasil. Possivelmente, é a representação de um indivíduo com menor poder aquisitivo.

Cabe ressaltar que a ilustração difere-se das demais que acompanhavam os anúncios no jornal referentes às associações esportivas. Os anúncios dos clubes de tiro, cavalaria ou ginástica, assim como as demais publicidades de grupos de bolão, eram comumente acompanhados por um símbolo característico da prática com pequenas variações entre os clubes. Tais símbolos, respectivamente, apresentavam dois armamentos cruzados um sobre o outro (clubes de tiro), um alvo de lançaria (clubes de cavaleiria), o símbolo dos 4Fs (Frisch, Fromm, Frei, Frölich ${ }^{9}$ ) (clubes de ginástica) e nove círculos desenhados conforme a disposição dos pinos do jogo (clubes de bolão).

O aviso referente à ilustração analisada é do clube de bolão Neuntöter (Nove Mortos) a respeito de um Preisschiessen - torneio de tiro com distribuição de prêmios oferecido pela associação e aberto ao público (RETTUNG-PIKADE, 1910). A construção da imagem remete a uma representação de momento descontraído e alegre, possivelmente, visando atrair o público para o evento regado a bebida, música e diversão. Esta estratégia de um evento aberto à comunidade, segundo os indícios encontrados, poderia visar o arrecadamento de dinheiro para o clube. Da mesma forma, a representação de um sujeito com menor poder aquisitivo pode traduzir um artifício de ressignificação no imaginário construído em torno da prática, como um elemento passível de lazer e consumo a todos.

\footnotetext{
${ }^{9}$ Puro, devoto, livre, alegre.
} 


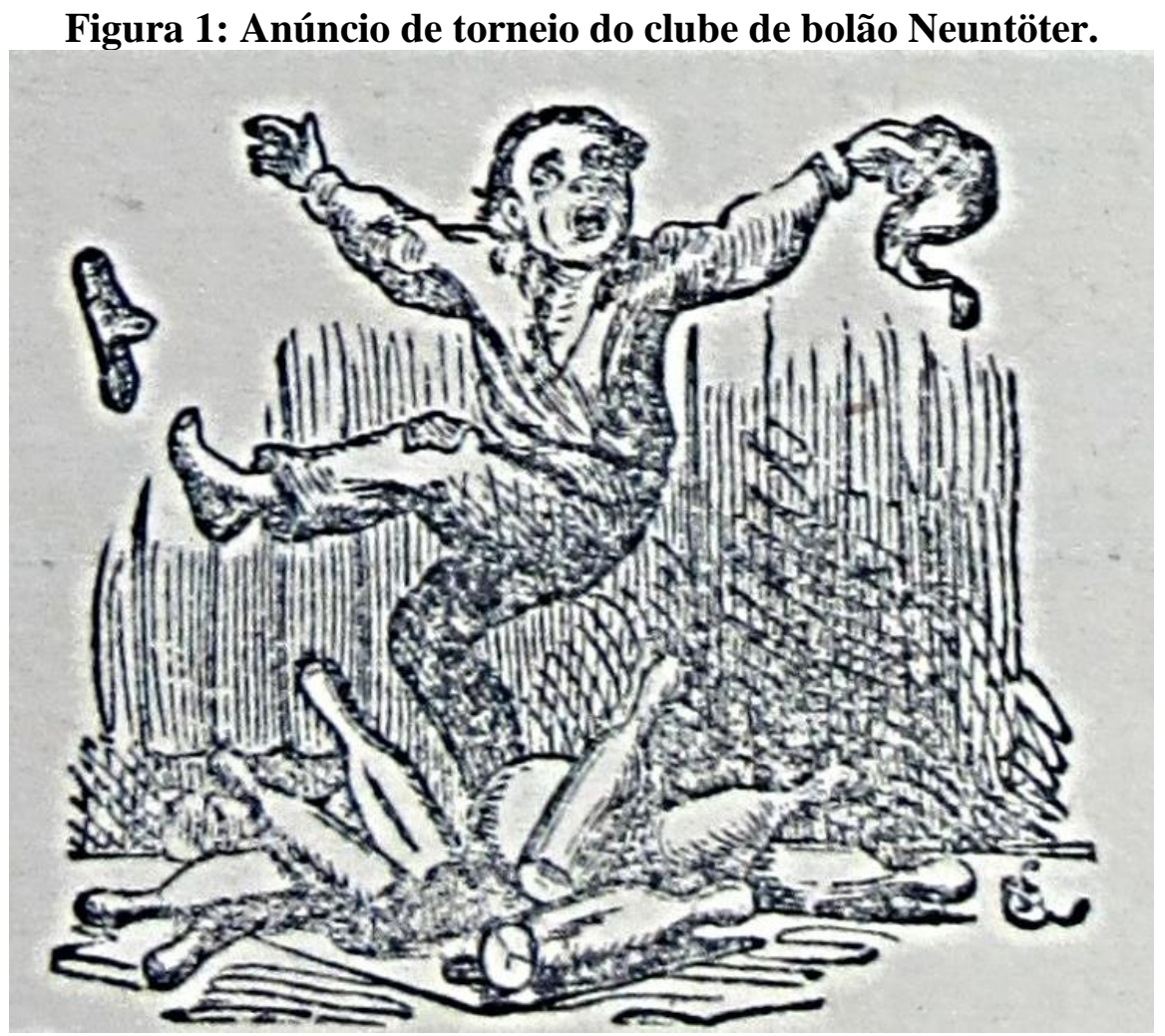

Fonte: RETTUNGS-PIKADE, 22 out. 1910

Segundo Kreling (1984), os eventos que admitiam a ingestão de bebidas alcoólicas, geralmente a água ardente na maioria das colônias, não eram vistos com bons olhos. O consumo excessivo resultava em tumulto e gritaria, prejudicando o bom andamento dos atos religiosos que se realizavam na capela próxima. A despeito disso, os religiosos também utilizavam a prática em seu benefício, promovendo, por exemplo, eventos de bolão para angariar recursos financeiros para a igreja (KRELING, 1984).

Os eventos e a contribuição financeira dos sócios eram fundamentais para a manutenção dos clubes/grupos. Conforme a estatística apresentada pelo jornal Kolonieem setembro de 1891, o grupo de bolão Millionenklub (Clube do Milhão), que desenvolvia suas atividades no Clube União, em Santa Cruz do Sul, contava com 20 membros e uma renda anual de 120 Mil reis por sócio (STATISTIK, 1891). Além do aporte dado pelos sócios, evidencia-se em anúncio do jornal Kolonie os eventos promovidos pelo grupo, por meio dos quais também eram angariadas contribuições dos 
sócios:Preiskegeln (torneios de bolão), Königskegeln (rei do bolão) e Picknick (piquenique) (MILLIONEN-KLUB, 1893).

O Clube União é listado na estatística apresentada pelo jornal Kolonie, em 1891, como aquele que possui a maior quantidade de associados, total de 100 sócios, dentre asGesellschaft (associações) e com a mais alta contribuição anual para cada sócio: 2:400 Milreis (STATISKI, 1891). Conforme estes dados, podemos deduzir que este clube era frequentado por indivíduos com alto capital econômico, tendo em vista àquela contemporaneidade. Ainda, é possível relacionar a associação como um espaço de acumulo de lucro social (BOURDIEU, 2003). Nesta mesma estatística, aparece como presidente da associação, o primeiro presidente do jornal Kolonie e político local, Carlos Trein Filho. Por conseguinte, o Clube União também passou a ser um local destinado às reuniões políticas (AM VERGANGENEN, 1891) e às assembleias do jornal (NOTIZ, 1891). Cabe salientar que apesar da existência de um grupo de bolão em sua sede, o Millionenklub, as publicações referentes ao Clube União não faziam alusão à prática. Com exceção de um parágrafo publicado em junho de 1892, afirmando que "no Clube União é a algum tempo assiduamente jogado bolão" (KEGELKLUB, 1892).

Outro ponto que chama a atenção quanto ao Clube União e pode estar relacionado à publicação referida acima, é a utilização do espaço como local de reuniões do diretório do Partido Federal em 1891, sendo escolhido como presidente do diretório o então líder do mesmo clube, Carlos Trein Filho (AM VERGAGENEN, 1891). Importa ressaltar que no período da publicação sobre o Kegelklub (1892) perpassavam movimentos de disputas políticas que já no ano seguinte decorreriam no advento da Revolução Federalista (1893-1895). A manifestação sobre o desenvolvimento da prática do bolão no clube pode ser intencional, buscando vincular e afirmar o espaço a uma representação de associação esportiva. É importante também levar em consideração o 
título de tal publicação: Clube de Bolão. Logo, o bolão parece ter sido apropriado, em determinados momentos, como forma de produzir uma representação do clube como espaço social/esportivo e, de tal modo desvinculado de um caráter eminentemente político.

Para além das apropriações acima referidas, evidenciou-se o bolão como um jogo que ascendeu no município de Santa Cruz do Sul no período de transição do século XIX para o século XX e teve continuidade mesmo diante das adversidades da Primeira Guerra Mundial (1914-1918). Inclusive, em 1917, ano que os teuto-brasileiros sentiram com mais veemência as disposições decorrentes da guerra, foi fundada uma associação de bolão de damas, chamada de Kegel-Bahn (KEGEL-BAHN, 1917). De acordo com os indícios encontradas até o momento, esta é a primeira associação voltada para a prática do jogo do bolão pelas mulheres ${ }^{10}$ de Santa Cruz do Sul.

Outra associação que aderiu à prática do bolão, nessa conjuntura, em Santa Cruz do Sul, foi a sociedade ginástica da localidade - Turnverein Santa Cruz - fundada em 1893. A prática do bolão foi introduzida no clube em 1916. Para além das adversidades provenientes do período da Primeira Guerra Mundial, que podem ter fomentado a necessidade de novas práticas e momentos de encontro e divertimento, a associação construiu, em 1915, a nova sede do clube (ASSMANN; MAZO, 2012). Além da instrumentalização intrínseca à prática, ou seja, seu caráter autotélico é possível que o bolão também estivesse atrelado à necessidade de acúmulo de capital financeiro para esta demanda, pois, conforme Hobsbawn (1975) o fim da I Guerra Mundial estava conectado a uma globalização do capitalismo. Assim, tal contexto pode ter possibilitado que novas associações esportivas incorporassem o jogo do bolão, devido a uma

\footnotetext{
${ }^{10}$ Em Porto Alegre um grupo de mulheres teuto-brasileiras, frequentadoras da Sociedade Leopoldina, organizou, em 1918, o Grupo de Bolão Violeta Arco-Íris (MAZO, 2003).
} 
instrumentalização extrínseca à prática, relacionada a uma função específica, atrair frequentadores e angariar dinheiro.

\section{Considerações Finais}

O jogo do bolão adquiriu diversificadas composições em associações esportivas étnico-culturais teuto-brasileiras, ao longo as décadas entre 1860 e 1920, no Rio Grande do Sul. Além de estar presente em diferentes localidades do estado, essa prática estava envolvida por elementos de identidade teuto-brasileira, que a ressignificava, e de distinção social, por envolver valores econômicos para a sua perpetuação. Diante disso, conquistou espaços em associações esportivas teuto-brasileiras como prática de lazer, ao possibilitar divertimento pela competição e o risco, gerados para os participantes e os expectadores, em forma de apostas. A partir destas representações, a prática do jogo do bolão atraia frequentadores para clubes e estabelecimentos próximos, estimulando o consumo e aumentando a renda, o que propiciou a sua instrumentalização como veículo para aquisição de capital econômico.

Portanto, infere-se que a prática do bolão, em Santa Cruz do Sul, parece ter sido apropriada para fins que extrapolavam sua compreensão como distração e espaço para sociabilidades. Dentre estas, destacam-se as apropriações econômicas, como forma de angariar valores para determinados fins.Outro ponto de destaque foi o número de anúncios no jornal Kolonie sobre as associações de bolão, a qual evidencia a divulgação e consumo midiático quanto a assuntos vinculados à prática pelos leitores.

\section{REFERÊNCIAS}

75 JAHRE Deutschtum. Livro Comemorativo. Santo Angelo Agudo, 1932.

AM VERGANGENEN Sonntag. Kolonie, Santa Cruz do Sul, 08 ago. 1891. Encontrado no Centro de Documentação da UNISC. 
ASSMANN, A. B.; MAZO, J. Z. As SCHÜTZENVEREINE (Sociedades de Atiradores) de Santa Cruz do Sul: um tiro certo na história do esporte no Rio Grande do Sul. Esporte e Sociedade, v. 7, p. 122, 2012.

O associativismo esportivo em Santa Cruz do Sul/Rio Grande do Sul: configurações de práticas culturais (da década de 1880 à década de 1910). Dissertação (Mestrado) - Escola de Educação Física, Universidade Federal do Rio Grande do Sul, Porto Alegre, 2015.

; MAZO, J. Z. Turnen: para além da ginástica: configurações dinâmicas em um espaço de práticas esportivas. Revista Brasileira de Educação Física e Esporte, São Paulo, v. 31, n. 2, 2017, p.489-503.

BOURDIEU, P. Como se pode ser desportista? In: BOURDIEU, P. Questões de sociologia. Tradução de Miguel Serras Pereira. Lisboa: Fim de Século, 2003.

BURGOS, M. S. et al. Jogos tradicionais e legado histórico dos descendentes alemães em Santa Cruz do Sul e Sinimbu-RS. In: MAZO, J. Z.; REPPOLD FILHO, A. R. (org.). Atlas do Esporte no Rio Grande do Sul: atlas do esporte, da educação física e atividades de saúde e lazer no Rio Grande do Sul. Porto Alegre: CREF2/RS, 2005.

CAILLOIS, R. Los juegos y los hombres: la máscara y el vértigo. México: Fondo de Cultura Económica, 1986.

CALONGA, M. D. O jornal e suas representações: objeto ou fonte da história? Comunicação \& Mercado/UNIGRAN, v. 1, n. 2, edição especial, nov. 2012. P. 79-87.

CHARTIER, R. A história ou a leitura do tempo. Belo Horizonte: Autêntica Editora, 2009.

DIAS, C. História das ginásticas em Goiás (1866-1916). Revista de História Regional, v. 19, n. 2, 2014, p. 386.

FACHEL, J. F. Os grupos de bolão e os "kränzchen" em Santa Cruz do Sul. In: FACHEL, J. F. Separata dos Anais do Primeiro Colóquio de Estudos Teutobrasileiros. Porto Alegre: Gráfica da UFRGS, 30 jul. 1964.

HOBSBAWM, E. Era dos extremos: o breve século XX. Rio de Janeiro: Paz e Terra, 1975.

HUIZINGA, J. Homo Ludens, Edição: Perspectiva, 1996.

JENKINS, K. A História repensada. 3. ed. São Paulo: Contexto, 2004.

KEGEL-BAHN. Kolonie, Santa Cruz do Sul, 04 jun. 1917.

KEGELKLUB. Kolonie, Santa Cruz do Sul, 25 jun. 1892.

KILPP, C. E.; MAZO, J. Z.; LYRA, V. Um olhar histórico sobre a emergência dos primeiros clubes esportivos na cidade de Teutônia no Rio Grande do Sul. Pensar a Prática, Goiânia, v. 13, p. 1-16, 2010. 
KILPP, C. E. O turnen e o esporte nas associações teuto-brasileiras de Estrela/Rio Grande do Sul. 2012. Dissertação (Mestrado em Ciências do Movimento Humano) Escola de Educação Física, Universidade Federal do Rio Grande do Sul, Porto Alegre, 2012.

KIPPER, M. H. A nacionalização em Santa Cruz do Sul. In: MÜLLER, Telmo L. (org.). Nacionalização e imigração alemã. São Leopoldo: mimeog, 1967.

KRELING, H. M. O Bolão: o esporte nas colônias alemãs do RS. Porto Alegre: Martins Livreiro, 1984.

MARTIN, H. E. Santa Cruz do Sul: de colônia a freguesia, 1849-1859. Santa Cruz do Sul: Associação Pró-ensino de Santa Cruz do Sul, 1979.

Recortes do passado de Santa Cruz.Organizado e atualizado por Olgario Paulo Vogt e Ana Carla Wïnsch. Santa Cruz do Sul: Edunisc, 1999.

MASCARENHAS, G. A Bola nas Redes e o Enredo do Lugar: uma geografia do futebol e de seu advento no Rio Grande do Sul. 2001. Tese (Doutorado em Geografia) Universidade de São Paulo, São Paulo, 2001.

MARQUES, W. E. U. Lazer, pesquisa e interdisciplinaridade: algumas reflexões acerca do contexto atual das produções acadêmicas. Licere, v. 15, n. 2, jun/2012. DOI: https://doi.org/10.35699/1981-3171.2012.731

MAZO, J. A nacionalização das associações esportivas em Porto Alegre (1937-1945). Movimento, Porto Alegre, v. 13, n. 3, p. 43-63, 2007.

MAZO, J. Z. Bolão no Rio Grande do Sul. In: MAZO, J. Z.; REPPOLD FILHO, A. R. (org.). Atlas do Esporte no Rio Grande do Sul: atlas do esporte, da educação física e atividades de saúde e lazer no Rio Grande do Sul. Porto Alegre: CREF2/RS, 2005.

Emergência e a Expansão do Associativismo Desportivo em Porto Alegre (1867-1945): espaço de representação da identidade cultural teuto-brasileira. Tese (Doutorado) - Faculdade de Educação Física e Ciências do Desporto, Universidade do Porto, Porto, 2003.

MILLIONEN-KLUB. Kolonie, Santa Cruz do Sul, 11 mar. 1893. Encontrado no Centro de Documentação da UNISC.

MÜLLER, T. L. Colônia Alemã: história e memórias. Caxias do Sul: EST, 1978.

Cluster esportivo de Santa Cruz do Sul. In: DA COSTA, Lamartine (org.). Atlas do esporte no Brasil. Rio de Janeiro: CONFEF, 2006.

NOTIZ. Kolonie, Santa Cruz do Sul, 24 out.1891. Encontrado no Centro de Documentação da UNISC.

OLIVEIRA, P. G. Esportes trazidos pela imigração. In: FISCHER, Luis Augusto; GERTZ, René (coord.). Nós os teuto-gaúchos. Porto Alegre: UFRGS, 1996. 
PESAVENTO, S. J. História e História Cultural. 2. ed. Belo Horizonte: Autêntica, 2004.

PEREIRA, E. L.; MAZO, J. Z.; BALBINOTTI, C. A. Federação Rio-Grandense de Tênis: mudanças impostas pelo Decreto-Lei no 3.199 de 1941. Recorde: Revista de História do Esporte, v. 3, n. 2, p. 1-27, dez. 2010.

RAMOS, E. O teatro da sociabilidade: os clubes sociais como espaço de representação das elites urbanas alemãs e teuto-brasileiras - São Leopoldo 1858-1930. 2000. Tese (Doutorado em História) - Instituto de Filosofia e Ciências Humanas, Universidade Federal do Rio Grande do Sul, Porto Alegre, 2000.

RETTUNGS-PIKADE. Kolonie, Santa Cruz do Sul, 22 out. 1910. Encontrado no Centro de Documentação da UNISC.

ROCHE, J. A Colonização Alemã e o Rio Grande do Sul. Porto Alegre: Globo, 1969.

SEYFERTH, G. As identidades dos imigrantes e o meltingpot nacional. Horizontes Antropológicos, Rio de Janeiro, v. 14, p. 143-176, 2000.

SILVA, H. O Imigrante e a rua: imagens da cidade de Porto Alegre na perspectiva de quem chega. Revista Social, n. 10, 2003.

SILVA, H. R. K. A identidade teuto-brasileira pensada pelo intelectual AloysFriederichs. Anos 90, Porto Alegre, v. 12, n. 21/22, p. 295-330, jan./dez. 2005.

SILVA, C. F.; MAZO, J. Z. Uma história das instrumentalidades do esporte no campo do associativismo esportivo em Porto Alegre/RS. Movimento, v. 21, n. 2, abr/jun, 2015, p. 377-389.

; MAZO, J. Z.; TAVARES, O. O estabelecimento dos esportes náuticos no Rio Grande do Sul na primeira década do século XX: entre o ruder e o remo. Revista Brasileira de Ciências do Esporte, v. 40, n. 1, 2018, p. 24-31.

STATISTIK, Kolonie, Santa Cruz do Sul, 19 set. 1891.

SUITS, B. The grasshopper: Games, life and utopia. Toronto: University of Toronto Press, 1978.

TESCHE, L. O Turnen, a Educação e a Educação Física nas escolas teutobrasileiras no Rio Grande do Sul (1852-1940). Ijuí: Editora UNIJUí, 2001.

WESCHENFELDER, G. A imprensa alemã no Rio Grande do Sul e o romancefolhetim. 2010. 146 f. Dissertação (Mestrado em Comunicação Social) - Faculdade de Comunicação Social, Pontifícia Universidade Católica do Rio Grande do Sul, Porto Alegre, 2010.

ZICMANN, R. B. História através da imprensa - algumas considerações metodológicas. Projeto História, São Paulo, jan/dez, 1985. 


\section{Endereço das Autoras:}

Alice Beatriz Assmann

Rua Rodolfo Simch, 275, apto 503 - Jardim Lindóia

Porto Alegre - RS - 91.050-350

Endereço eletrônico: alice.assmann @uemg.br

Carolina Fernandes da Silva

Campus Universitário - Trindade

Florianópolis - SC - 88.040-900

Endereço eletrônico: carolina.f.s @ufsc.br

Janice Zarpellon Mazo

Avenida Lucas de Oliveira, 2507, apto 402 - Bairro Petrópolis

Porto Alegre - RS - 90.630-084

Entedereço eletrônico: janice.mazo@ufrgs.br 